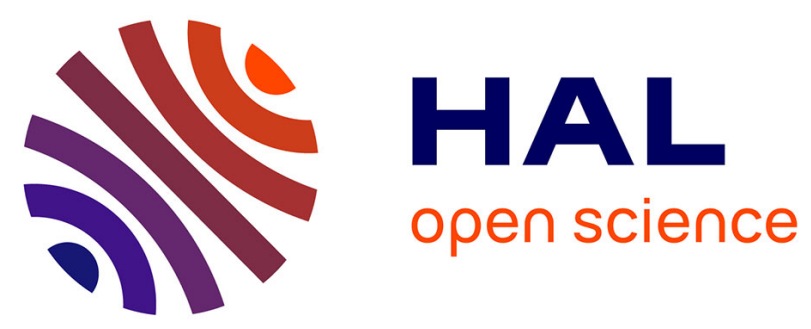

\title{
Reading with a digital roll
}

Clément Pillias, Pierre Cubaud, Shuo-Hsiu Hsu

\section{To cite this version:}

Clément Pillias, Pierre Cubaud, Shuo-Hsiu Hsu. Reading with a digital roll. CHI 2013, Apr 2013, Paris, France. pp.1377-1382, 10.1145/2468356.2468602 . hal-01111648

\section{HAL Id: hal-01111648 \\ https://hal.science/hal-01111648}

Submitted on 30 Jan 2015

HAL is a multi-disciplinary open access archive for the deposit and dissemination of scientific research documents, whether they are published or not. The documents may come from teaching and research institutions in France or abroad, or from public or private research centers.
L'archive ouverte pluridisciplinaire HAL, est destinée au dépôt et à la diffusion de documents scientifiques de niveau recherche, publiés ou non, émanant des établissements d'enseignement et de recherche français ou étrangers, des laboratoires publics ou privés.

\section{(이) $\$$}

Distributed under a Creative Commons Attribution - NonCommercial - NoDerivatives $\mid 4.0$ 


\section{Reading With a Digital RoII}

\section{Clément Pillias}

CNAM/CEDRIC, ILJ Team

292 rue Saint Martin

75003 Paris, France

clement.pillias@cnam.fr

\section{Shuo-hsiu Hsu}

CNAM/CEDRIC, ILJ Team

292 rue Saint Martin

75003 Paris, France

xocialhsu@gmail.com

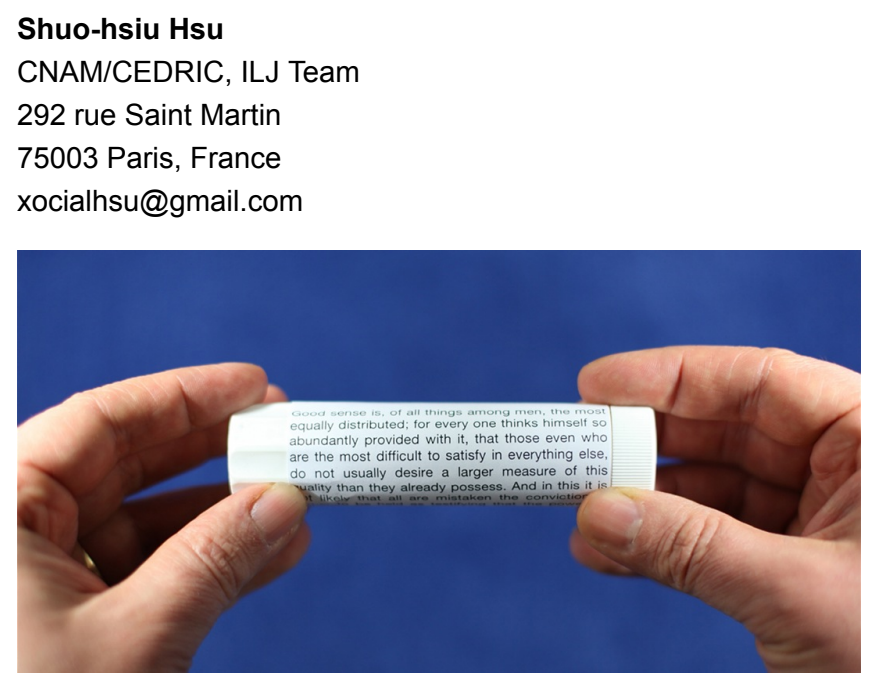

Figure 1: The digital roll (paper mock-up).

Copyright is held by the author/owner(s).

CHI 2013 Extended Abstracts, April 27--May 2, 2013, Paris, France. ACM 978-1-4503-1952-2/13/04.

\author{
Pierre Cubaud \\ CNAM/CEDRIC, ILJ Team \\ 292 rue Saint Martin \\ 75003 Paris, France \\ cubaud@cnam.fr
}

\begin{abstract}
(2)
\end{abstract}

\begin{abstract}
We introduce the Digital Roll, a cylindrical hand-held device wrapped with a curved display, that can be rotated by hand to provide a continuous scrolling of text. We present design considerations for such a device and report on a preliminary experiment designed to assess its acceptance for casual reading, using a simulator. Encouraging results and their implications on the design of the device are then discussed.

\section{Author Keywords}

E-books; E-readers; reading; scrolling; curved display.

\section{ACM Classification Keywords}

H.5.2 [User Interfaces]: Input devices and strategies; H.5.2

[User Interfaces]: Interaction styles.

\section{Introduction}

The need for small, hand-held and compact reading devices is old and universal and has fueled many innovations in the history of reading [5]: In late antiquity, the papyrus scroll was replaced by the codex, a manuscript version of the modern book. During the renaissance period, emergent needs for mobility led to the creation of the first "pocket books." Innovation with paper continues: In 2009, Dutch editor Jongbloed created the Dwarsligger, a book concept of reduced size that uses horizontal binding. But obviously, it is digital technology that gathers today's attention. E-readers are now considered by consumers to be superior to print for
\end{abstract}




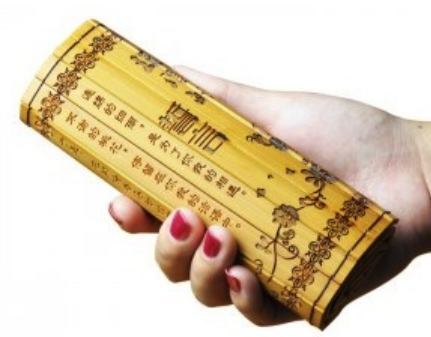

Figure 2: Contemporary Chinese scroll.

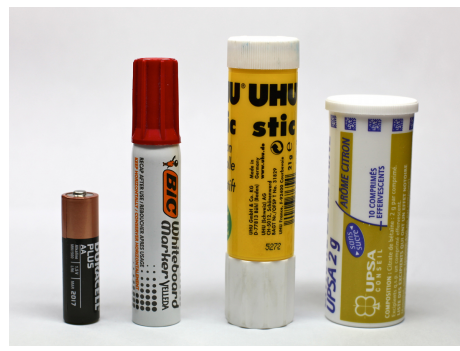

Figure 3: Prints on cylindrical manufactured objects.

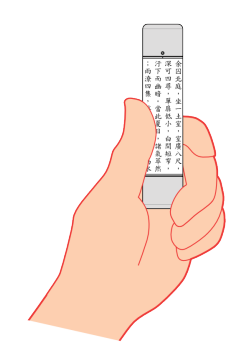

Figure 4: Use of the digital roll for Chinese or other vertically organized writing system. reading on the move [10]. However, interaction with such devices is still limited compared to their paper counterparts. Fortunately, thin and flexible display technologies such as E-Ink and OLED offer new opportunities to bridge this gap.

In this paper, we study the roll shape as a reading surface, proposing in a way to revamp the antique scroll. Fig. 1 shows a mock-up of a digital roll, a hand-held digital device with cylindrical screen shape that allows a continuous scrolling of text using motion capture. A digital roll has a smaller form factor than a flat e-reader with similar screen surface. This could make it useful for readers on the move, such as commuters.

As with many e-readers, applications of digital rolls are limited due to technical considerations, e.g., image and video visualization seem pointless on a cylindrical display because of the distortion. Navigation within structured multimedia documents, such as Web pages, is therefore improbable. In addition, one can fear that the digital roll would inherit the well known drawbacks of the paper scroll: small reading context, difficult navigation and text skimming. However, many reading activities such as reading novels for pleasure are mostly sequential processes. Navigation through this kind of document could thus benefit from the infinite, continuous display offered by the digital roll. As novels are the most popular e-books bought by readers, ${ }^{1}$ we believe the digital roll may fill some kind of niche in the ecosystem of mobile appliances.

Related work Reading scrolls continue to be used in Chinese culture (fig. 2) but, in general, reading on cylindrical shapes is mostly limited to instructions printed on manufactured goods (fig. 3). Some designs of digital devices based on cylindrical displays have been patented [3]. As far

${ }^{1}$ In Jan. 2013, the top-30 bestsellers on the Amazon portal were all novels. as we know, however, their potential use for reading devices has never been evaluated. Reading on a curved screen has been studied on short texts that do not require rotation of the device [6]. Folding, bending and rolling devices are being systematically investigated as an alternative to flat displays for media appliances [7, 9, 8].

Research questions and methods Digital rolls have three obvious potential drawbacks: (1) reading text on a cylindrical screen causes a distortion of letters that could make the text harder to read, (2) turning the roll could cause fatigue during long reading sessions and (3) the small display area reduces the amount of context that one can have. We are interested in finding how these issues (and other less evident ones) affect the reading experience with digital rolls. In early discussions with potential users, most of them expressed concerns about these issues. However, one minute of interaction with the paper prototype shown in figure 1 alleviated most of these concerns. We thus hypothesize that their impact on the reading experience is low.

We present in this paper the results of a preliminary experiment designed to roughly evaluate the overall impact of these issues, discover other overlooked issues, validate our design considerations and get basic knowledge of how users would operate the device during longer reading sessions. To conduct this research, we built a digital roll simulator, which is easier to build than a prototype and can be easily distributed. ${ }^{2}$ It also allowed us to separate the design of the display from the one of the input method. In the future, it will allow us to refine these designs in shorter cycles and to separately investigate the effects of the input method (turning the roll) and the distortion of letters.

\footnotetext{
${ }^{2}$ We provide a downloadable version that can be operated with a WiiMote at the URL: http://cedric.cnam.fr/ilj/d-roll/
} 


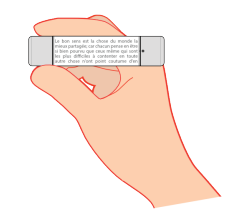

Figure 5: One-handed use of the digital roll for horizontal text.

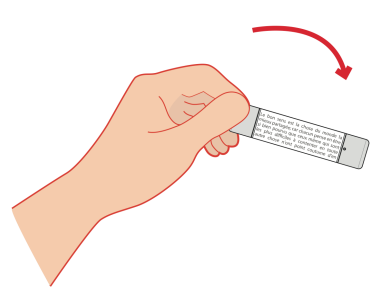

Figure 6: Example of a navigation gesture: shaking the roll to access menu.

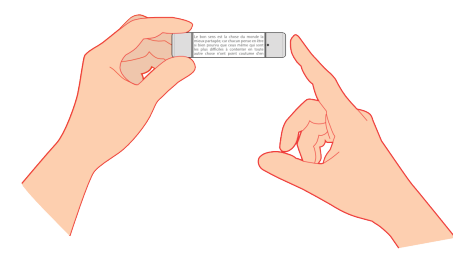

Figure 7: Another example of a navigation gesture: tapping the end of the roll to validate the choice of a menu item.

\section{Design Considerations}

The dimensions of the digital roll cannot be arbitrary. Roll diameter must obviously allow easy grip for the widest population. Since we target mobile use, a small volume is necessary. However, the roll should offer a usable display surface. For screen width, one can reproduce the width of a pocket book text line, which is 8 to $9 \mathrm{~cm}$. This value is common for commercial e-readers. The volume of a roll $9 \mathrm{~cm}$ wide and $3 \mathrm{~cm}$ in diameter is $64 \mathrm{~cm}^{3}$. It is about half the volume of the Txtr Beagle, currently advertised as the smallest e-reader [1], which is $100 \mathrm{~cm}^{3}$ with a 5 " screen.

Diameter impacts on the rotation speed one has to provide in order to have a text display rate consistent with reading speed. A reading speed of 500 words $/ \mathrm{min}$. is observed for good readers [4]. This may be considered as an upper bound for casual reading. A $9 \times 9 \mathrm{~cm}$ screen displays roughly 125 words (half of a pocket book page in 10 pt font). Rolls with such a screen must therefore be turned at 4 RPM in order to match a fast reading speed. We shall see in the next section that, in practice, the rotation speed is much lower.

Whether the roll rotation should be provided directly by the user's hands or indirectly using some automatic control is an important design issue. We believe that both modes could be offered to the user - if a properly tuned automated display can be found. Direct control clearly has the advantage of a lower degree of indirection and higher degree of compatibility [2] which should result in an easier use. So, in this preliminary work, we choose to study it first.

User's actions on the roll can be performed one-handed, or bi-manually. Ideally, the user should be able to change the operation mode during the reading. It is clear that one-handed rotation has a limited angular scope if the roll is pinched. However, continuous one-handed rotation is possible if the roll stays in the palm of the hand (fig. 4 and 5). This might be interesting in the case of vertically oriented text, such as Chinese. Accelerometer-based gesture recognition can be used to provide other required functions of an e-book reader, such as jumping between paragraphs or chapters, skimming or calling a menu to navigate in the library. The form factor of the device provides an interesting design space for creating such gestures, including bi-manual ones (see fig. 6 and 7).

The display of text during roll rotation can be handled in various ways. The easiest solution is to refresh all of the screen when a specific roll angle is reached, which would correspond to the border of the screen. In this setting, the screen is refreshed once per roll turn, which would be suitable for a low-consumption E-ink display with slow refresh rate. OLED screens exhibit a higher refresh rate, so the text display can react in real time with the roll's motion. It is thus possible to display, at each angle change, a new "window" of the text. Fig. 8 shows the mapping rules of this window on the screen. This second operation mode provides a continuous move in the text. However, it requires a clever way to detect what part of the roll the user is looking at.

\section{Simulating the digital roll}

Input The sensor is based on an Intersense InertiaCube BT. This wireless inertial measurement unit offers a $0.5^{\circ}$ absolute angle precision at $180 \mathrm{~Hz}$ with low drift for a weight of $67 \mathrm{~g}$. As shown in fig. 9, this unit was encased in a hollow PVC tube so that its center of mass lies on the tube axis. The length of the tube is $11 \mathrm{~cm}$ and its diameter is $3.2 \mathrm{~cm}(2.8 \mathrm{~cm}$ internal), providing enough space to insert the thumbs, as it has no cap.

Output To accurately render the text distortion caused by the cumulated effects of perspective and cylindrical 


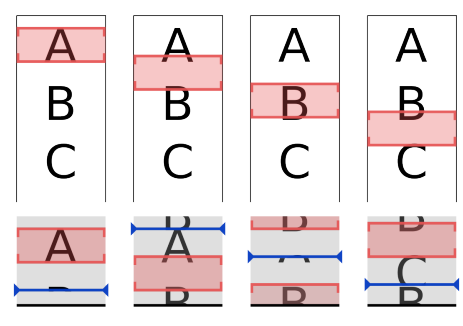

Figure 8: The top row shows, from left to right, some (unrolled) text while it is read. The red rectangle indicates the visible part of the roll.

The bottom row shows the content of the roll display and how it is updated. The blue line separates what will be read next (above it) from what has already been read (bellow it).

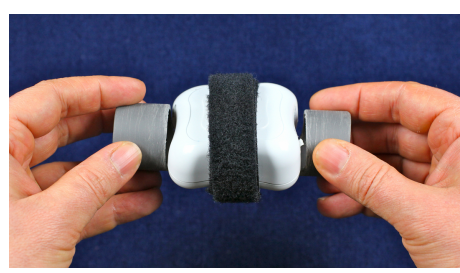

Figure 9: Input device for motion capture.

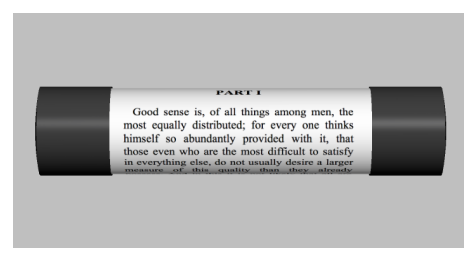

Figure 10: Simulating the roll. Screenshot of the 3D application. projection, we use a two-pass OpenGL renderer: the content of the virtual roll display is first rendered in an OpenGL texture, then this texture is mapped on a cylinder using 16:1 anisotropic filtering and lightning. The first pass uses the Berkelium library that provides an off-screen OpenGL rendering of Google's Chromium open-source web browser. This allows a high-quality rendering of text with a great flexibility, as CSS3 and javascript are very well supported. In addition, we reorder the virtual screen content as explained in fig. 8. We used a virtual display size of $1000 \times 942$ pixels, mapped on a $10 \mathrm{~cm}$-long cylinder (without the handles) with a $3 \mathrm{~cm}$ diameter. This provides a virtual resolution of $254 \mathrm{dpi}-$ now common on high-end mobile phones, but not on computer displays that need to render the roll bigger than its real size.

\section{Preliminary Experiment}

Task During the experiment, subjects had to read a short but complete novel: Le Passe-muraille (The

Passer-through-Walls) by Marcel Aymé. Task completion time was expected to be around 15-20 minutes, since the novel is 3580 words long. The novel is at a middle school reading level and is renowned for its humor. We hoped these qualities would encourage subjects to readily talk about their feelings during reading, make comments, ask questions and suggest improvements.

Subjects A call for participation was sent to our institution's staff mailing list, asking for volunteers who read regularly on their free time and especially when commuting. Thirteen participants answered the call ( 7 women, 6 men), aged from 28 to 65 year old (mean: 43.4, $\sigma: 11.4$ ). All subjects but one were right-handed. Eleven read books on a daily basis and 6 were frequent users of digital devices for casual reading.
Apparatus We ran a modified version of the simulator in fullscreen on a 27" iMac placed on a stand so that the bottom of the screen was at approximatively the same height as the knees of the person sitting in front of it. The display occupied most of the visual field of the subjects who had to slightly bend the head in order to look at the simulated roll, but not as much as if they were holding the real object on their laps. A video camera positioned one meter above the display took $\mathrm{HD}$ recordings of the subjects' hands during interaction. The simulator logged the sensor state (position in space) and the display state (total amount of rotation of the roll, i.e., part of the text that was visible). The novel was typeset in the Cambria font so that its line spacing and number of words per line matched that of the paper edition.

Protocol Subjects were first asked to fill in a one-page form about their personal data and their paper and digital reading habits. They were then asked to sit in front of the (then blank) simulator display and were given the paper prototype shown in fig. 1 and very short oral explanations about the digital roll. The simulator then displayed a virtual roll holding more detailed information about the task and instructions such as "roll until next paragraph," to ensure the subjects got some basic practice manipulating the sensor before the actual trial. Subjects were instructed to find a comfortable posture, possibly changing the chair settings and apparent size of the virtual roll in order to compensate for any change of distance to the screen. The simulator then displayed a new roll with the novel. Subjects had to call the experimenter when they reached its end. Finally they had to fill out a one page survey about their experience with the simulator and possible usage of the digital roll. The session ended with open discussion.

Results The total reading time for each participant was between 10.3 and 25.3 minutes (mean: 15.8, $\sigma: 4.9$, median: 14.2 ), fitting in the planned interval. This suggests that 


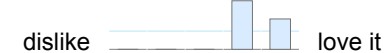

Appreciation of text

continual $\quad \square \square \square$ never

Attention to hands

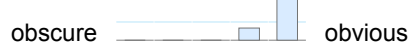

Roll: understandability

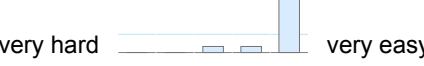

Roll: ease of use

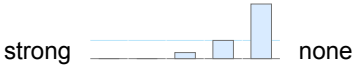

Hands strain

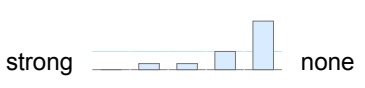

Eye fatigue

no $\square \quad \square \square \square$ yes

Would use in transports

$$
\text { no } \square \square \square \square \square \text { yes }
$$

Would use at home

no $\square \quad \square \square \square$ yes

Would use in vacations

Figure 11: Subjective evaluation results (5 values). Blue horizontal line represents 3 answers for the given value. reading on the simulated digital roll can be as fast as reading on paper, although it needs to be confirmed by a controlled experiment comparing the two. From an analysis of the logs, we noticed that some subjects read at an almost constant speed while others read faster at the end. This suggests that if there was any fatigue effect it may have been canceled by a learning effect, or simply because of the story's suspense. Indeed, fig. 12 shows that some parts of the text clearly require more or less time to be read.

We coded the recorded videos for significant events such as changes in overall posture of the subject or in finger position, signs of fatigue or distraction, and backward or unusually fast rotations. The coding scheme also tracked hands cooperation and scrolling synchronism: Hands cooperation may be symmetrical, when both hands do the same movement to turn the roll, then are repositioned in any order; alternating, when each hand turns the roll alternatively while the other one is repositioning; or asymmetrical, when one hand is used to turn the roll and the other one only provides guidance or support. Scrolling synchronism is a strategy that can also be defined for scrollable text in a more conventional setup: it may be parallel, when reading and scrolling are done at the same time, or alternating, when reading phases alternate with scrolling phases.

For hands cooperation, the symmetrical mode was barely used, and only when starting a move. The real surprise came from the very large dominance of the asymmetrical mode: all subjects used it most of the time, some only using this mode while only three subjects used the alternating mode for more than $30 \mathrm{~s}$. However, most subjects used it for fast rotations without reading. Interestingly, there was no clear effect of handedness on the choice of each hand's role and some subjects switched many times the roles of their hands. The scrolling synchronism strategy is harder to analyze and probably needs more data. However, we think it is an important factor to understand reading with the digital roll, as we have found that most changes in the reading speed were associated with changes in any strategy or in finger position.

There were a few variations on the finger positions, the most surprising being the insertion of some fingers inside the PVC tube. Four subjects tried such a position, using either the thumb, the index, or a combination of the index and major (most of the time with both hands, always with the same fingers for both hands). Two subjects made the whole trial using such a position, and one of them stated in the later discussion that the object would seem less usable without such holes in the handles.

Interview The questionnaire that users had to fill after the reading session was made of 5 -values rating scales, all balanced in positive and negative values (with the exception of Attention to hands that was asking for a frequency, from 'continually' to 'never', with intermediary steps 'often',

'sometimes' and 'once or twice'). Fig. 11 presents the results and clearly shows that the digital roll technique was easy to understand and to use, and caused no fatigue for reading sessions of this length. In the open discussion, four subjects expressed fears about using it during commuting because of the risk of theft, while two others stated that its shape would reduce that risk. Two also complained that with so little text displayed, the high level of distraction in such environments would rise the chance to loose the reading context. This issue was also raised by one subject as a justification for his frequent backward rotations during the experiment, since he usually reads in a rather non-linear way.

Implications for design Our findings about hands cooperation strategy have implications for the design of the roll, as it may be useful to have a fixed handle in one hand, 


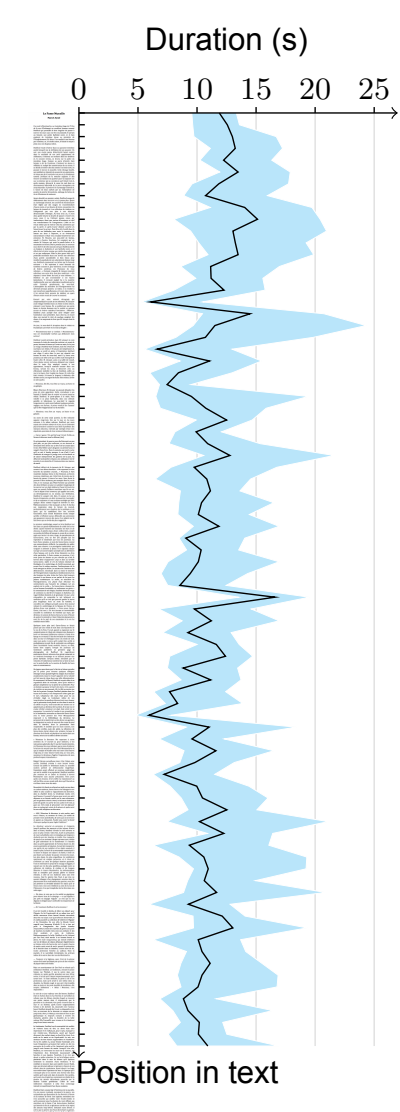

Figure 12: Reading durations: the novel has been truncated into segments such that 4 segments can fit on the roll. For each segment we computed the total time it was in front of the subject. The graphics displays for each segment the median time among subjects (black line) and the interquartile range (cyan polygon). the other handle turning with the screen (see fig. 5). Hollow handles might also be a requirement for some people and could help single-handed manipulation.

\section{Future Works}

We believe that these initial results are encouraging and that this research should be carried out. A methodological issue is to determine which results may be obtained concerning the user reading experience without having to build a prototype.

In the short run, we plan to continue the experiments using the simulator with other types of documents, such as Tweets and news. Subjects younger that our initial panel will also be studied. To this day, our simulator only allows sequential reading. No navigation action has yet been implemented and tested. Our next task will be to refine the interaction and gestures for intra-text navigation. We will then specify an $\mathrm{HCl}$ for the general management of the device. The 3D simulator and focus groups sessions should facilitate the choice between several design alternatives.

We also want to develop a more advanced capture device, with dimensions corresponding to the targeted digital roll. We shall add touch sensors to investigate further the fine movement of the user's fingers during the rotation of the roll and the potential of these manipulations for interaction.

In the longer run, a prototype carrying a cylindrical screen must be developed, following for instance [9] guidelines. It would enable the study of reading on the move with the digital roll and interesting comparisons with current flat page-based devices.

\section{Acknowledgements}

This work has been partly funded by the ANR CONTINT

Transread project.

\section{References}

[1] http://us.txtr.com/beagle/.

[2] Beaudouin-Lafon, M. Instrumental interaction: an interaction model for designing post-wimp user interfaces. In Proc of $\mathrm{CHI}, \mathrm{CHI}$ '00, ACM (New York, NY, USA, 2000), 446-453.

[3] Cho, Y. M. Mobile terminal using flexible display and method of controlling the mobile terminal. Patent US2010/0117975 A1, May 2010.

[4] Dehaene, S. Reading in the Brain: The New Science of How We Read. Penguin Group US, 2009.

[5] Fischer, S. A history of reading. Globalities Series. Reaktion Books, 2003. (pp. 83-87).

[6] Häkkinen, J., Pölönen, M., Salmimaa, M., and Hautanen, J. Reading experience with curved hand-held displays. Journal of the Society for Information Display 16 (2008).

[7] Khalilbeigi, M., Lissermann, R., Kleine, W., and Steimle, J. Foldme: interacting with double-sided foldable displays. In Proc. of TEI, TEI '12, ACM (New York, NY, USA, 2012), 33-40.

[8] Khalilbeigi, M., Lissermann, R., Mühlhäuser, M., and Steimle, J. Xpaaand: interaction techniques for rollable displays. In Proc. of CHI, CHI '11, ACM (New York, NY, USA, 2011), 2729-2732.

[9] Lahey, B., Girouard, A., Burleson, W., and Vertegaal, R. Paperphone: understanding the use of bend gestures in mobile devices with flexible electronic paper displays. In Proc. of CHI, CHI '11, ACM (New York, NY, USA, 2011), 1303-1312.

[10] Rainie, L., Zickuhr, K., Purcell, K., Madden, M., and Brenner, J. The rise of e-reading. http://libraries. pewinternet.org/2012/04/04/the-rise-of-e-reading/, April 2012. Verified on $5^{\text {th }}$ of January, 2013. 